\title{
LAS PINTURAS NEGRAS DE GOYA Y LA QUINTA DEL SORDO. PRECISIONES SOBRE LAS TEORÍAS DE JUAN JOSÉ JUNQUERA
}

\author{
POR \\ NIGEL GLENDINNING \\ Queen Mary, Universidad de Londres
}

En 2003, tres publicaciones de Juan José Junquera pusieron en tela de juicio la paternidad de las Pinturas Negras de Goya. El presente artículo cuestiona las conclusiones del profesor Junquera, examinando con detalle la base documental de sus teorías.

Palabras clave: Pintura española; Francisco de Goya; Pinturas Negras.

In 2003, three publications of Juan José Junquera cast doubt on the authenticity of Goya's Black Paintings. The present article disputes the validity of Professor Junquera's conclusions and re-examines the relevant documents in detail.

Key words: Spanish Paintings; Francisco de Goya; the Black Paintings.

Es muy justo que se revisen constantemente las fuentes de información que tenemos sobre las vidas y las obras de los grandes pintores, y hay que agradecer al profesor Junquera el interés que ha puesto en volver no hace mucho a los archivos, para compulsar nuevamente los documentos en torno a las Pinturas Negras y la Huerta de Goya (o Quinta del Sordo). Bastante menos de agradecer, en cambio, es su modo de exponer sus conclusiones y sus dudas sobre la paternidad de la famosa serie. Las sacó a luz primero en la revista Descubrir el arte (V, no. 51 , 2003, pp. 23-32), sin el aparato crítico necesario. Luego publicó su libro, Goya. The Black Paintings (Londres: Scala Books, 2003), que no constituía, por desgracia, un paso hacia delante, sino más bien un extraño piétinement sur place. Los lectores avisados — que habían leído su artículo sobre las Pinturas Negras- reconociendo en la nueva publicación el eco de sus primeros disparos contra las ideas recibidas, se sorprenderían de que las siguiera tratando, la mayor parte del tiempo, como si no hubiese puesto antes en tela de juicio su autoría. Los vecinos de las calles de Caramuel y Juan Tornero, por su parte, y los aficionados a Goya que conocían el sitio en que se ubicaba antiguamente la Quinta, se quedarían pasmados al ver reproducido en su libro el lienzo de Aureliano de Beruete titulado La pradera de San Isidro, como si en aquel cuadro se pudiera ver la Casa del Sordo, tal como estaba a principios del siglo xx (Figs. 1 y 2$)^{1}$.

${ }^{1}$ En su libro The Black Paintings of Goya, Londres, Scala Books, 2003, p. 29, Junquera sustituye, por equivocación, La
Casa del Sordo (1907), de Beruete, por La pradera de San Isidro (1909). Ni el uno ni el otro debiera de titularse Perspec- 

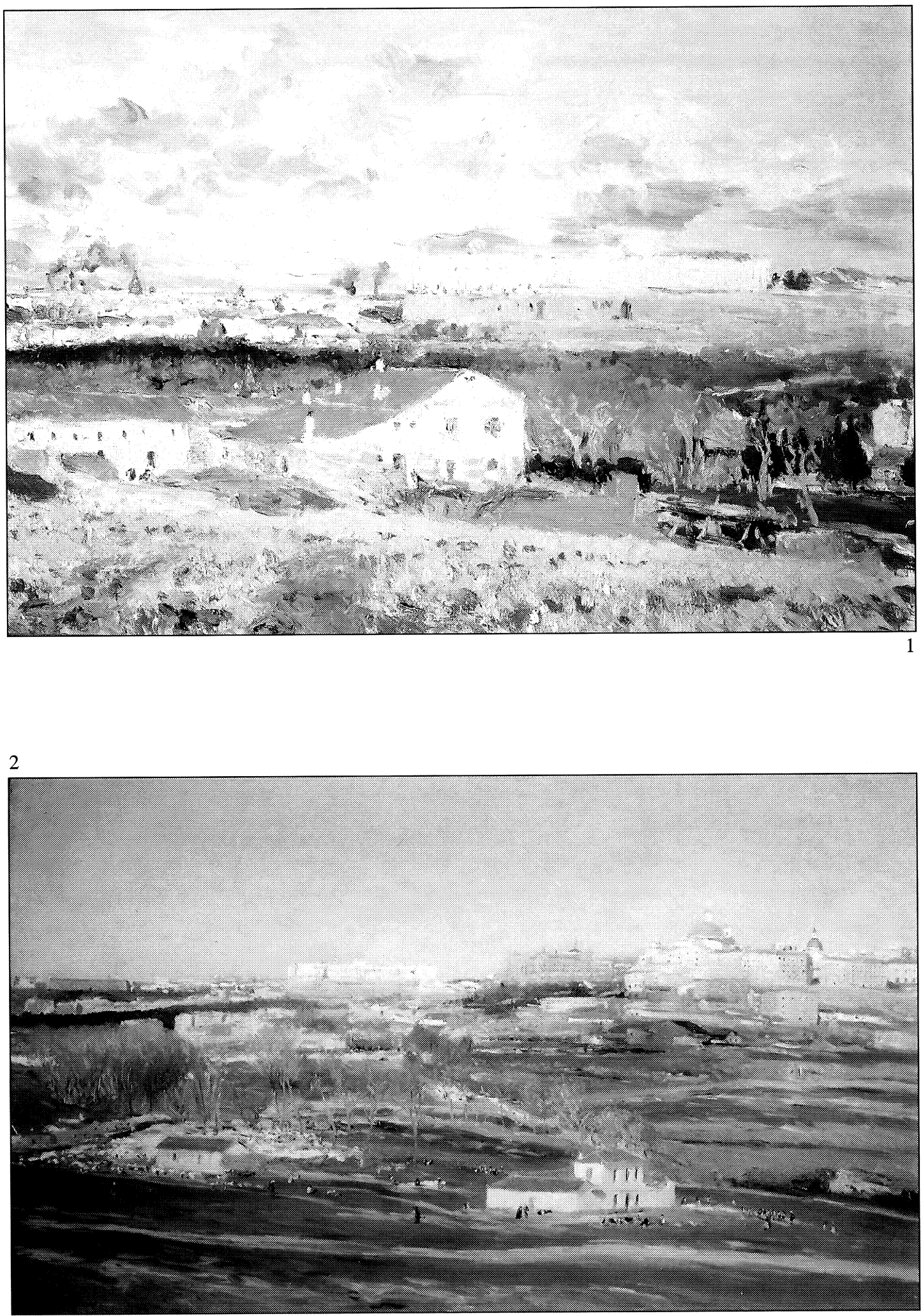

Fig. 1. Aureliano de Beruete, La Casa del Sordo, Madrid (1907). Madrd, Museo del Prado No. 4255. Fig. 2. Aureliano de Beruete, Pradera de San Isidro (1909). Madrid, Museo del Prado, No. 4245.

AEA, LXXVII, 2004, 307, pp. 233 a 245 
Los estudiosos de Goya esperaban que todo quedara aclarado en el artículo que publicó después en Archivo Español de Arte (LXXVI, 2003, 304, pp. 353-370). Pero allí tampoco ha expuesto Junquera con suficiente rigor sus teorías, ni explicado su interpretación de las fuentes de manera adecuada. Parece muy necesario, por lo tanto, examinar de nuevo los textos básicos y demás materiales utilizados por el mencionado profesor, para ver hasta qué punto son sostenibles las conclusiones que ha sacado de ellos, atribuyendo las Pinturas Negras al hijo del pintor, Javier; manteniendo que la Quinta no tenía más que una sola planta, con desván encima, en tiempo de Goya; y tratando de demostrar que la sala del primer piso (y la mitad de las pinturas por lo menos) no se hubieran podido pintar hasta que la casa se ampliara después de la muerte del genial artista.

\section{La Quinta o Huerta de Goya}

Ya dio Francisco Javier Sánchez Cantón en 1946 los detalles más notables acerca de la casa de recreo comprada por Goya, sacados de la escritura de venta otorgada por Pedro Marcelino Blanco a favor del artista en 27 de febrero de $1819^{2}$. En este documento se hizo constar que la casa había sido construida (o reedificada) ${ }^{3}$ por don Anselmo Montañés, ayudante militar de las Reales Fábricas y Casco de Palacio, sobre un terreno de cinco fanegas comprado en 1795. Allí levantó «una Casa de Campo de fabrica de adoves con su jardin unido; dos habitaciones bajas distribuidas en diferentes piezas, un pozo de agua potable inmediato á dicho jardin, y otro en un patio de las habitaciones y dos desvanes, y tambien plantó por la parte del arroyo en el centro de la tierra cinco alamos blancos». Esta frase parece referirse a la construcción de una serie de edificios y facilidades: casa (de número de pisos sin especificar), jardín, dos habitaciones bajas —o sea, dos edificios o alas habitables de un solo piso- dos pozos, y un grupo de árboles. El profesor Junquera, en cambio, prefiere una interpretación de este texto bastante distinta, sosteniendo que las habitaciones bajas constituían la casa misma.

Para aclarar mejor el asunto, es menester recurrir a otros documentos y otras fuentes de información, que Junquera ha pasado por alto. Ayuda algo la escritura de venta de la posesión, otorgada por la viuda de Anselmo Montañés a Pedro Marcelino Blanco en julio de 1806, en la que se dan algunas precisiones más sobre la finca, no recogidas en el documento de $1818^{4}$. Reproduzco a continuación el texto de 1806 , poniendo en cursiva las palabras omitidas en la escritura posterior.

«Construyó [don Anselmo Montañés en las tierras] vna Casa de Campo de fabrica de Adobes, con su Jardin vnido á la misma, dos abitaciones baxas, distribuidas en siete piezas, vn pozo de Agua potable inmediato al propio Jardin, y otro en vn patio de las referidas havi-

tiva de Madrid desde la Quinta de Goya (View of Madrid from Goya's Quinta) como Junquera supone. En el más temprano de estos cuadros, se mira la Quinta desde el suroeste y desde un sitio ligeramente más alto. El Palacio flota, por así decirlo, encima de la casa, y ésta se pone de relieve contra un fondo de tonos oscuros. Vemos que el tejado, por detrás -que sólo conocemos gracias a este cuadro - llega a la planta baja, y ha desaparecido el ala que prolongaba la fachada oriental en los dibujos de mediados del siglo xix. Sin duda se deshizo cuando se sacaron las Pinturas Negras de las paredes de la casa principal. Sigue en su sitio, en cambio, la gran ventana en medio de la pared lateral de la sala del primer piso. Véase Museo del Prado, Casón del Buen Retiro, Catálogo de las pinturas del siglo xix, Madrid, Ministerio de Cultura, 1985 , pp. 38-40, n..$^{\text {s }} 4245$ y 4255.

2 Sánchez Cantón, F.J., «Cómo vivía Goya», Archivo Español de Arte, Madrid, No. 74, abril-junio, 1946, p. 94. Hemos cotejado el texto publicado por Sánchez Cantón con el de la escritura (AHPM, P. ${ }^{\circ} 22.788$, f. 85r), para corregir algunos errores de transcripción.

${ }^{3}$ Según la escritura, la viuda de Montañés habla de la venta de la «casa que ... había reedificado su difunto marido» (AHPM, P. 22.786, f. 86v, Miguel Calvo García, 1819).

${ }^{4}$ AHPM, P. ${ }^{\circ} 22.146$, f. 657r - 672r. Félix Pico de Haedo, 20 de julio de 1806. 
taciones, y dos desbanes; e igualmente plantó cinco Alamos blancos por la parte del Arroyo en el centro de las referidas tierras» ${ }^{5}$.

En este texto de 1806, se separan más claramente la casa y su jardín, por un lado, de las habitaciones bajas, por otro. Hay menos posibilidad de confundir la una con las otras, y parece probable que el patio de las habitaciones consistiese en un espacio rectangular o cuadrado - abierto por un lado - formado por la misma casa y dos alas de una sola planta, con desvanes encima. Por desgracia, tampoco en esta descripción se explicita el número de pisos que la casa principal tenía, y hay que volver a otras fuentes que arrojen más luz sobre este aspecto del edificio.

El documento más esclarecedor a este respecto es, sin duda alguna, la fotografía de la fachada oriental de la casa, sacada en fecha desconocida, pero hacia fines del siglo xIx, a juzgar por los vestidos y trajes que llevan las cuatro personas de pie en primer término, y, sobre todo, la chaqueta corta y chaleco que el señor, que se destaca a la derecha, lleva - el dueño de la quinta, se supone (Fig. 3) ${ }^{6}$. Menos útiles, en relación con la historia de la casa, son los dibujos de mediados del siglo XIX reproducidos, respectivamente, en el libro sobre Goya de Charles Yriarte (1867) y en un artículo del mismo autor publicado en la revista francesa L'Art en 1877 (Fig. 4) ${ }^{7}$, porque introducen errores o simplificaciones en la representación de las contraventanas, y ofrecen menos claridad que la fotografía en los detalles. Resulta valioso también, en cierto modo, el inventario «Brugada», que especifica las Pinturas Negras que había en el piso principal lo mismo que en la planta baja en los años veinte del siglo xIx y, con toda probabilidad, antes de la muerte de Goya ${ }^{8}$. Tanto la fotografía como el inventario constituyen argumentos fuertes en contra de las teorías de Junquera, y a pesar de que este último haya puesto en entredicho la fecha de redacción del inventario, sus argumentos histórico-lingüísticos son muy poco convincentes, como luego veremos.

La fotografía referida divide la fachada en tres partes: la de la izquierda, la entrada principal en medio, y la parte habitable más ancha a la derecha. Consta que la ampliación de la casa, llevada a cabo después de la muerte de Goya, empezaba con la puerta central. Esta daba acceso a una gran escalera para subir del zaguán al primer piso, y a los cuartos y dormitorios nuevos $^{9}$. El estilo del marco de la ventana a la izquierda, en el primer piso, y el de la modesta puerta de madera debajo de la misma — caída en desuso, sin duda, después de la construcción del gran portal - parecen confirmar la relativa antigüedad de la primera crujía a la izquierda. En ella, la puerta de abajo y la ventana por arriba están más hundidas en sus respectivos marcos, y las contraventanas están ubicadas dentro de la casa y no fuera, como en la parte (más moderna) a la derecha. De esto se deduce que el grosor de los muros de la primitiva casa era bastante mayor en la parte vieja que en la ampliación; otro indicio de la relativa vejez de los

\footnotetext{
${ }^{5}$ Id., f. 664 r.

${ }^{6}$ Fotografía tomada por Asenjo, reproducida en La Ilustración Española y Americana, LIII, Madrid, 15 de julio de 1909, n. ${ }^{\circ}$. 16, p. 19. En su libro The Black Paintings of Goya, Londres, Scala, 2003, p. 25, Juan José Junquera supone erróneamente que el negativo de la fotografía se realizara en 1873.

${ }^{7}$ El dibujo de Ferat, basado en una fotografía de la fachada y grabado por Coste, se reproduce en Yriarte, Ch., Goya, París, Henri Plon, 1867, p. 91; el dibujo grabado para la revista L'Art, IX, 1877, tomo 2, p. 9, es de Saint-Elme Gautier.

${ }_{8}$ Algunos folios del inventario obraban en poder de la viuda de Brugada, y fueron copiados por Xavier Desparmet FitzGerald hacia 1875, siendo este último alumno en Burdeos de Amédée Baudit, el yerno de esta señora. Puede, por lo tanto, que haya algunos errores por parte del copista, que ahora resulten imposibles de identificar. El texto de la copia se publicó en Desparmet Fitz-Gerald, X., L'CEuvre peint de Goya. Catalogue raisonné illustré de 447 reproductions suivies de 34 dessins inédits, Ouvrage posthume publiée avec un supplément par Mlle. Xavière Desparmet Fitz-Gerald, París, F. de Nobele, 1928-1950, I, pp. 53-54. Para las circunstancias en las que se sacó la copia, véase la nota 1 en la p. 40.

9 Véase Yriarte, Ch., ob. cit., p. 92. («son fils a fait élever la partie à droite de la grille qui forme une maison plus confortable»).
}

$A E A$, LXXVII, 2004, 307, pp. 233 a 245 

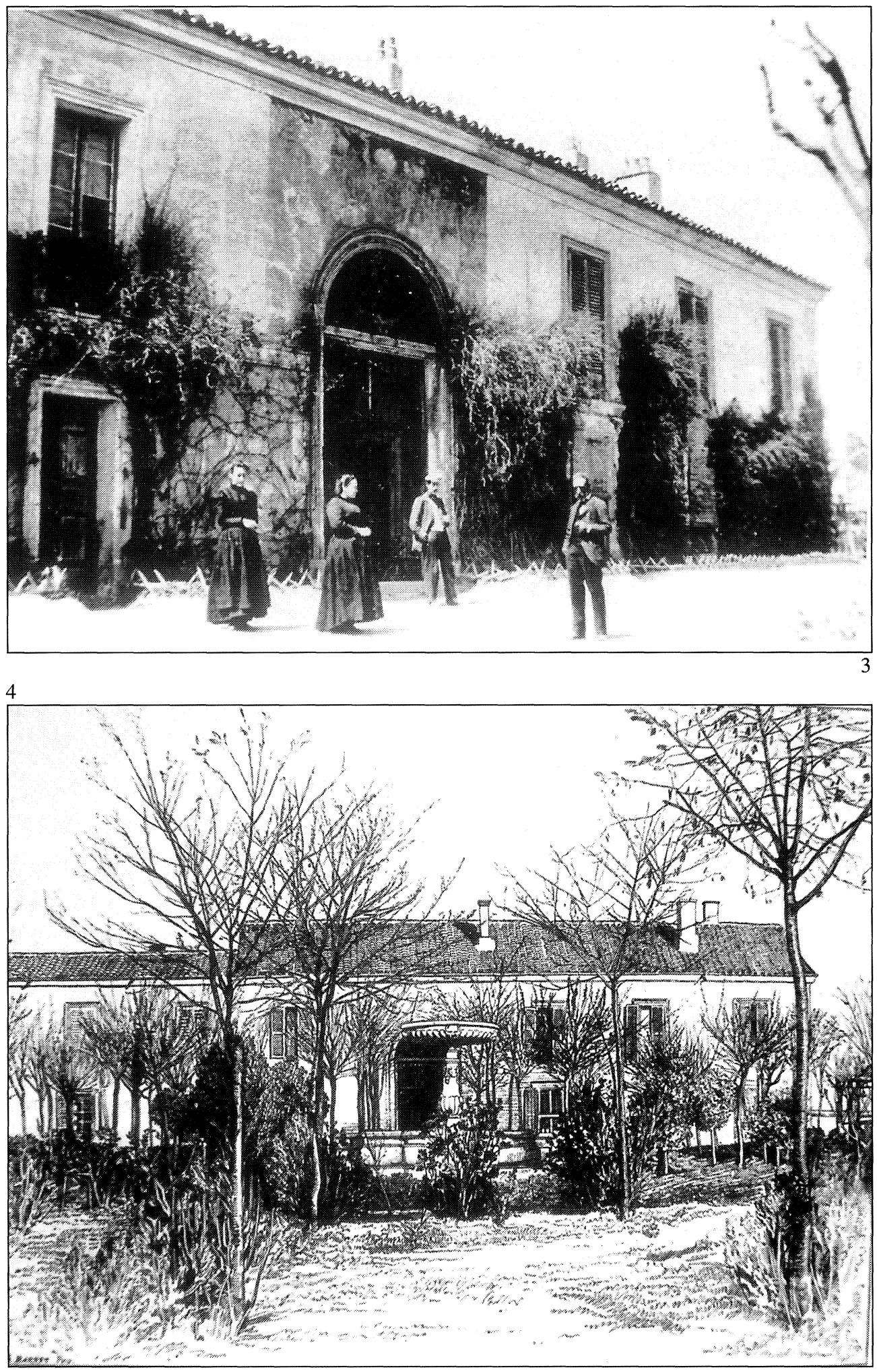

Fig. 3. Fotografía tomada por Asenjo de la fachada principal de la Quinta de Goya (ca. 1900). La Ilustración Española y Americana, LIII, Madrid, 15 de julio de 1909, p. 19.

Fig. 4. Saint-Elme Gautier, Dibujo de la Quinta de Goya. Reproducido en L'Art, IX 1877, tomo 2, p. 9. 
dos pisos a la izquierda. Las contraventanas interiores, además, eran macizas y no dejarían entrar la luz del día, mientras que las exteriores estaban compuestas de tablillas fijas, y la luz filtraría por ellas, siguiendo asimismo el estilo más moderno. La colocación de las chimeneas es también sugerente en los dibujos. Se ven las bocas de tres de ellas a la derecha y ninguna a la izquierda, como si se calentara la primitiva casa al estilo antiguo, con braseros, cuya eficacia, calor humano y valor social elogiara con tanta gracia en 1841 Mesonero Romanos, en un artículo en que se mofaba de la moda de las recién importadas chimeneas francesas, suizas e inglesas ${ }^{10}$. Es una lástima que no se haya podido averiguar, hasta ahora, la fecha del ensanche de la Quinta. Pero lo más probable es que se construyera durante el período de mayor estabilidad a principios de los años cuarenta, después de la primera Guerra Carlista y la epidemia de cólera, para quedar terminada quizás hacia 1846, como sugeriremos más adelante.

Apoya nuestra interpretación del carácter de la casa comprada por Goya en 1819, un documento bastante posterior, que pudimos consultar en el Registro de Propiedad de Madrid, en una época en que el acceso a los índices y los libros de aquel archivo era más fácil para los investigadores de lo que es ahora. La finca núm. 142 en el tomo 33 del Registro del Partido de Madrid (tomo con el número antiguo de 74) es «la posesión titulada Quinta de Goya de las tierras conocidas con el nombre de Flores», y se describía tal como estaba después de ser comprada por don Segundo Colmenares el 1 de junio de 1859. He aquí el texto que nos interesa; los subrayados son nuestros:

«Dentro de dicha posesion se encuentran construidos varios edificios marcados en el plano con numeracion, que consisten el numero primero en la construccion de una casa de recreo compuesta de planta baja y piso principal que tenga una superficie de cuatro mil trescientos diez y ocho pies siendo frente de ella la primitiva casa del célebre pintor Goya, en la que existen varias pinturas en las paredes, las cuales están bastante deterioradas, y el resto de la construccion mas moderna, pero todo en buen estado y decorado el exterior con cornisas de yeso y estucadas las fachadas, asi como el vestibulo y escalera...»

La palabra clave en este pasaje es «frente», que significa en este contexto «lo primero que se ofrece a la vista en el edificio», o quizás también el ángulo formado por dos muros que se juntan en determinado lugar. Parece evidente que, con ella, se quiere señalar el extremo izquierdo de la casa: el extremo por donde, en Occidente, se suele empezar la contemplación de los cuadros y perspectivas. Es cierto que también a la izquierda existía, a continuación del frente aludido, un ala menos alta que la casa principal, que se ve en los grabados de la época. A esta ala se le da un número distinto en el plano mencionado en el registro, en el que se le describe de la siguiente manera:

«el numero dos adherido al anterior edificio solo tiene planta baja y desvanes para granos distribuida en habitaciones para el jardinero, cuarto de herramientas ${ }^{11}$, y ocupa tres mil quinientos veinte y siete pies».

Este edificio se define más adelante en el mismo documento como «la prolongación de la primera crujía» de la casa principal: prolongación sin duda hacia el sur, constituyendo el ala que se ve en los grabados mencionados.

\footnotetext{
${ }^{10}$ Mesonero Romanos, R., «Al amor de la lumbre o el brasero», Escenas matritenses, segunda época (1836-1842) [1851], ed. facsímil, Madrid, Abaco, s.a., pp. 193-194.

${ }^{11}$ El cuarto de herramientas referido quizás pueda ser el misterioso «cuarto de los áz.s» mencionado en una escritura de arriendo de la Quinta y sus muebles, fechada el 13 de abril de 1857 (AHPM, P. ${ }^{26.523}$, f. 289r - 292v). Puede que la abreviatura corresponda al sustantivo «acemileros».
}

AEA, LXXVII, 2004, 307, pp. 233 a 245 
Es, desde luego, una lástima que la casa primitiva no aparezca en la maqueta de Madrid, construida en 1830 y conservada en el Museo Municipal, para que la viéramos de bulto, tal como era en tiempos de Goya. Pero la Quinta queda, por desgracia, justo fuera de los límites del modelo, aunque parte del terreno que le pertenecía tiene que haberse incluido en la maqueta, junto al Camino de San Isidro. Aparece la casa, desde luego, en diversos planos de Madrid, mas tan sólo con indicios esquemáticos de la configuración de los edificios en los más tempranos. En el de López (1812) parece tener forma rectangular y no se señala la existencia de alas. En los de Tardieu (1825) y Donnet (1823), en cambio, consta de tres secciones, que podrían ser la casa principal y dos alas. Los planos nada nos dicen del número de plantas, claro está, pero había bastantes casas con dos pisos en la zona, a juzgar por las que se pueden ver en la maqueta del Museo Municipal.

\section{Información deducida de los inventarios}

El profesor Junquera ha deducido la presencia de una colgadura de percal en alguna habitación de la casa, del inventario de bienes llevados a su matrimonio por Mariano Goya en $1830{ }^{12}$. Y le parece poco probable que se hubiese pintado nada sobre este tipo de tela. Pero el inventario, en realidad, no dice que la colgadura servía para cubrir la pared, sino que era tan sólo para adorno de una cama que pertenecía a Mariano. El apartado es como sigue:

«Ytt, Colgadura de percal con fleco para dicho ... ciento veinte [reales]» ${ }^{13}$.

La palabra «dicho» en este caso se refiere al «catre» tasado en una anotación anterior, y no a la habitación en la que se encontraba.

En cuanto al inventario de Brugada, que nos proporciona los primitivos títulos de las pinturas negras ejecutadas en los dos pisos de la Quinta, Junquera emplea dos tácticas para poder desechar la evidencia de este texto: primero, tratar de descartar la posibilidad de que el documento original se preparase en los años veinte del siglo xIX; y en segundo lugar, dar fechas de introducción más tardías a tres términos empleados en la descripción de algunos de los muebles inventariados, o sea, «maqueado», «vargueño» $\mathrm{y}$ «estilo Luis $\mathrm{XV}{ }^{14}$. Sigue Junquera, por cierto, las conclusiones de otros estudiosos, al poner en tela de juicio la posibilidad de que Brugada ayudase a Javier Goya a levantar este inventario de los bienes de Goya después de la muerte del artista en 1828, como antes se había supuesto. Pero pasa por alto la posibilidad de que Brugada hubiera podido ayudar a Goya a hacer tal inventario en 1823, antes de marcharse a Francia.

Los argumentos a favor de una fecha tardía para el inventario - que Junquera quiere que se date hacia 1859 o incluso $1870{ }^{15}$ — basándose en las supuestas épocas en que determinadas

\footnotetext{
12 Junquera y Mato, J.J., «Las Pinturas Negras, bajo sospecha. Un nuevo estudio discute la autoría de Goya», Descubrir el Arte, V, n. ${ }^{\circ}$ 51, 2003, p. 27 («en la sala, precisamente una de las habitaciones supuestamente pintadas por Goya, las paredes estaban cubiertas con una colgadura de percal»).

${ }_{13}$ Véase «Capital de los bienes que lleva a su matrimonio D. Pío Mariano de Goya», AHPM, P. 22,887, f. 26 - 33.

${ }^{14}$ Juan José Junquera y Mato, art. cit., p. 23.

${ }^{15}$ En el artículo que publicó en Descubrir el Arte (p. 29), Junquera suponía que el inventario pudiera haberse levantado en 1859, pero cambia de ideas y sugiere una fecha más tardía en su libro The Black Paintings of Goya, Londres, Scala, 2003, p. 33, afirmando que algunas de las palabras y expresiones empleadas en el inventario no circulaban en España hasta la segunda mitad o fines del siglo xIx. Por fin, en el artículo dado a luz por Archivo Español de Arte (p. 358), se pregunta si el inventario se habrá redactado hacia 1878, es decir, después de la fecha en que Desparmet Fitz-Gerald dijo que había sacado la copia y después de la muerte de Mariano Goya, que Junquera supone responsable de «una manipulación ... para meter de matute algunos falsos [cuadros de Goya]».
} 
palabras o frases empezaban a circular, resultan evidentemente insostenibles. Fijar la fecha en que empieza a circular determinada palabra o frase es notoriamente difícil. Ninguno de los ejemplos aducidos se relaciona con una invención nueva, ni son del tipo de neologismo introducido para designar fenómenos o técnicas nuevos, que son las únicas clases de locución que se pueden datar con cierta seguridad. «Vargueño» (o «bargueño»), por ejemplo, es un adjetivo relacionado con el pueblo de Vargas (ahora escrita con B en vez de V), en la provincia de Toledo. Y el profesor Junquera afirma que su uso como sustantivo - para definir un tipo de escritorio de los siglos XVI y XVII, cuya fabricación se asociaba sobre todo con aquel pueblo toledano- data de 1879, cuando lo emplea Juan Facundo Riaño. Pero Junquera se olvida de decirnos que Riaño, al explicar el término, afirmaba que era de uso muy antiguo y no era de nuevo cuño, y es lógico concluir que se empleara entre los expertos de muebles en el siglo XIX antes de Riaño ${ }^{16}$.

En cuanto al adjetivo «maqueado», al parecer derivado de una palabra japonesa, es verosímil que llegara a Europa con otras importaciones orientales en el siglo xviII. Encontré el adjetivo, por pura casualidad, en un contexto español que parece apoyar esta teoría, al revisar un inventario protocolizado en 1835 , hace varios años. Se trata del «Ynventario y tasacion de los muebles y efectos existentes en la casa del Difunto $\mathrm{Ex}^{\mathrm{mo}}$ é $\mathrm{Ilt}^{\mathrm{mo}} \mathrm{S}^{\text {or }} \mathrm{D}^{\mathrm{n}}$ Ignacio Omulryan y Rouera de Berart», aragonés de estirpe irlandesa retratado por Goya en 1817. En el apartado de los adornos de su casa se encuentra la anotación siguiente:

«Ytt. 1 Caja grande maqueada en dorado con dos botes de tée» ${ }^{17}$.

Teniendo en cuenta esta cita de los años treinta no debe sorprendernos la presencia de la palabra «maqueado» en el inventario Brugada en el caso de que fuera, en efecto, levantado en los años veinte, en vida de Goya.

Más difícil de fechar es la introducción de frases como «estilo Luis $\mathrm{XV}$ ». Parece lógico partir una vez más del siglo XviII para explicar los orígenes de expresiones de este género, porque fue por entonces cuando Voltaire propuso que las épocas de Luis XIV y XV se considerasen dignas sucesoras de las edades de Alejandro y Augusto en las culturas grecorromanas. Ya, a fines del siglo XvIII, se describía el estilo de algunos edificios franceses como «de la época de Luis XIV», y, en España, empleó esta fórmula el marqués de Ureña en un contexto arquitectónico más de una vez, en la relación de su viaje por Europa en 1787 y $1788^{18}$. Con tales antecedentes, la idea de asociar el estilo de un mueble francés con el reinado de uno de estos reyes, no habrá tardado mucho en difundirse, y tampoco debe extrañarnos mucho en un documento de la segunda década del siglo XIX.

\section{Referencias tempranas a las Pinturas Negras}

El profesor Junquera hace especial hincapié en la escasez de referencias tempranas a las pinturas murales de la Quinta, como si los documentos y los impresos recogiesen siempre los comentarios emitidos acerca de las obras de arte más recientes. ¡Ojalá fuera así! Nos frustran además dos advertencias insuficientemente concretas sobre la vida y la obra de Goya, que es posible aludiesen precisamente a las Pinturas Negras: primero, la de Ceán Bermúdez, cuando

\footnotetext{
16 Véase Riaño, J.F., The Industrial Arts in Spain, Londres, Chapman \& Hall, 1879, p. 120.

17 AHPM, P. ${ }^{\circ} 24.214$, José de Amezúa, 1824 -1835.

${ }^{18}$ Véase, por ejemplo, El viaje europeo del marqués de Ureña (1787-1788), ed. María Pemán Medina, s.1., Unicaja, 1992 , pp. $144-5$ y 161.
}

AEA, LXXVII, 2004, 307, pp. 233 a 245 
dice en su Historia de la pintura —aún sin publicar - que había visto a Goya pintar con los dedos, sin decirnos en qué época ni dónde ${ }^{19}$; y, en segundo lugar, la nota de Federico Madrazo advirtiéndonos que habría de redactar sus recuerdos de Goya para ampliar sus Memorias en torno a los años 1826 y $1827^{20}$. ¿Los redactó en efecto? ¿Diría algo allí de las Pinturas Negras? No lo sabemos y es inútil darle más vueltas, ya que no podemos deducir nada de estas noticias para nuestro caso, ni en sentido positivo, ni menos en negativo. Pero con respecto a la autenticidad de las pinturas murales de la Quinta, resultan más que suficientemente claras las observaciones acerca de ellas que se encuentran en Le Magasin pittoresque (1834) y en la biografía de Goya por Valentín Carderera, publicada en el Semanario pintoresco (1838), muy poco después de la muerte del genial pintor. El autor del artículo francés subraya el hecho de que Goya había pintado él mismo «toutes les murailles» de su «villa délicieuse»; capta, exagerándolas, la audacia y la libertad de la técnica empleada; y supone que había incluido - como es cierto - en algunas de las pinturas escenas de la historia contemporánea ${ }^{21}$. Carderera, por su parte, considera el conjunto de las pinturas de la Quinta como una de las «luminosas pruebas» de su «práctica al temple y al fresco», y pone de realce el estilo imaginativo y caricaturesco de las obras pintadas por Goya en las paredes de aquella casa. Parece confirmar Carderera, por otra parte, la existencia del primer piso cuando se alude a lo que Goya había pintado en la escalera ${ }^{22}$.

Con respecto a los comentarios posteriores sobre las pinturas de la Quinta, Junquera se extraña de la ausencia de referencias a las mismas en los escritos de Pedro de Madrazo, olvidando, sin duda, lo que dijo este experto en su nota biográfica sobre Goya en el Catálogo descriptivo e histórico del Museo del Prado de Madrid (Parte primera, 1872). Reza así:

«La llamada Casa del Sordo, quinta de recreo de nuestro pintor, orillas del Manzanares, retenía aún, poco ha, 13 ó 14 cuadros suyos del mayor mérito» ${ }^{23}$.

No parece que Madrazo dudara de la calidad de las Pinturas Negras ni de su autenticidad.

\section{Fotografías de las Pinturas Negras}

Para sostener su teoría acerca de las Pinturas Negras, el profesor Junquera no tiene en cuenta datos que pudieran demostrar que aquellas pinturas ya estaban en las paredes de la Quinta antes de la ampliación de la casa. O sea, antes de 1846, más o menos, cuando Mariano Goya empezó a usar el título de marqués de Espinar, y era lógico que colocase - como en efecto colocó- las iniciales ME, con una corona de marqués encima, sobre la cancela de la nueva entrada de la Quinta ${ }^{24}$. Con respecto a las fotografías hechas por Laurent de las Pinturas Ne-

\footnotetext{
${ }^{19}$ Véase Glendinning, N., Goya y sus críticos, trad. María Lozano, Madrid, Taurus, 1982, p. 70. La cita —que se refiere también al uso de la punta del cuchillo por Goya para pintar - viene del quinto tomo de la Historia de la pintura, MS inédito de Ceán Bermúdez que obra en la biblioteca de la Real Academia de Bellas Artes de San Fernando, Madrid. Ceán dio principio a la redacción de este tomo en agosto de 1824.

20 Véase el catálogo de la exposición Federico de Madrazo (1815-1894), Madrid, Amigos del Museo Romántico, 1994, p. 56, y nota 110 .

${ }^{21}$ Véase Lafuente Ferrari, E., Antecedentes, coincidencias e influencias del arte de Goya, Madrid, Sociedad Española de Amigos del Arte, 1947, p. 309. Sustituimos «villa» por «ville» en la primera línea, de acuerdo con el original del texto francés.

${ }_{22}$ Semanario pintoresco, III, 1838, p. 632.

${ }^{23}$ Ob. cit., p. 406

${ }^{24}$ El marqués del Saltillo, en su libro Miscelánea madrileña, histórica y artística. Primera serie. Goya en Madrid, su familia y allegados (1746-1856), Madrid, Editorial Maestre, 1952, p. 49, demuestra que Mariano usaba el título de mar-
} 
gras, cuyas placas de cristal se conservan en el Archivo Ruiz Vernacci del Instituto del Patrimonio Histórico Español en Madrid, Junquera no quiere creer que se hiciesen en la Quinta antes de los años setenta; incluso supone que los negativos se tomaron cuando las pinturas ya habían ingresado en el Museo del Prado, puesto que las reseñas o fichas impresas que aparecen en los positivos afirman que allí se encontraban ${ }^{25}$. Pero la evidencia de las placas mismas es otra. Parece claro que se les pegó la reseña mucho después de que las placas se prepararon. Además, consta que se inscribieron números en la emulsión distintos de los que aparecen en las reseñas impresas; y estos números son inferiores y, por tanto, anteriores a los de las etiquetas. El perro, por ejemplo, lleva 2579 en la reseña, mientras que el número inscrito en la emulsión es H 381; los números de Atropos son respectivamente 2570 y H 383; los de La peregrinación a la fuente de San Isidro, 2567 y H 394; y los de Doña Leocadia, 2578 y H 382. Es una lástima que no sepamos la significación de la letra $\mathrm{H}$ aplicada a las Pinturas Negras, dentro de las series de negativos de Laurent, pero los números inscritos en la emulsión parecen hablar claro. Cotejándolos con los números dados a otras pinturas fotografiadas por Laurent, más fáciles de fechar, parece evidente que se les puede encajar en su producción a mediados de los años sesenta ${ }^{26}$. Además, el argumento a favor de una fecha relativamente temprana para estas placas de Laurent no depende sólo de precisiones de este tipo. Se basa en parte, también, en el estado de las pinturas y del ambiente a su alrededor, captado en las placas mencionadas: estado que en algún caso es muy parecido al que se ve en una estampa de la misma obra, grabada asimismo en los años sesenta (Figs. 5 y 6) ${ }^{27}$. Puesto que consta también que el $\mathrm{Sr}$. Coumont encargó fotografías de la serie cuando él era dueño de la Quinta, y las pasó a Charles Yriarte para que se hiciesen los grabados publicados en su libro, ¿por qué no serían las placas que conocemos de Laurent las que se hicieron precisamente con este fin? ${ }^{28}$. ¿No son los deterioros que se aprecian en paredes y pinturas - aquellas grietas que pasan claramente de las unas a las otras a través de los marcos, visibles sobre todo en los dos cuadros del lado septentrional del primer piso- muestras de la antigüedad de esta parte de la casa, que prueban que las pinturas llevaban bastante tiempo allí?

El hecho de que aparezcan trozos de pared, revestidos de papel pintado, alrededor de las pinturas en estas fotografías, es también significativo (Fig. 7). Los expertos europeos del papel pintado no excluyen la posibilidad de que los dos tipos de papel visibles -felpado en parte, probablemente, en el piso de abajo y estampado con taco de madera en el piso principalse hayan fabricado antes de $1820^{29}$. Los diseños de los papeles y las técnicas empleadas en

qués del Espinar ya en enero de 1847, y parece verosímil que lo hubiese comprado el año anterior. En la conocida fotografía de la fachada de la Quinta que daba al jardín, se pueden ver las iniciales ME y la corona, cuya explicación dio por primera vez Charles Yriarte en su libro Goya, p. 92.

${ }_{25}$ Véanse Juan José Junquera, en Descubrir el Arte, núm. cit., p. 23 («posteriores a 1879») ; en Archivo Español de Arte, núm. cit., p. 362 («posiblemente después de la donación del Barón d'Erlanger» y «la toma de las placas con las pinturas ya en El Prado»). Los números impresos en las reseñas pegadas a las placas (pertenecientes a la serie 2500 etc.) corresponden, sin duda alguna, a las fotografías reveladas por Laurent en los años ochenta del siglo xix. Pero los números inscritas en la emulsión son los que hay que tener en cuenta para establecer la fecha de esta serie de placas.

${ }^{26}$ Sabemos que los números más bajos, entre 1 y 100 , son de principios de los años sesenta, puesto que se dieron a cuadros de Murillo, Velázquez, y otros pintores que obraban en el Museo del Prado y se fotografiaron entonces. Consta también que las placas de algunos cuadros pintados en los años sesenta llevaban números entre 600 y 700 . El número 613 , por otra parte - cuadro de Poleró firmado y fechado en 1868 - tiene que haber sido fotografiado a fines de los años sesenta, porque la serie de negativos llegó a 800 a principios de los años setenta, ya que el cuadro No. 810 fue fotografiado en una exposición en 1871. Sacamos estas conclusiones de una selección de cuadros fotografiados por Laurent en el catálogo de la exposición J. Laurent, I (Madrid, Museo del Arte Contemporáneo, 1983).

27 Se puede comparar, por ejemplo, el aguafuerte de El Santo Oficio grabado por Gimeno para El Arte en España (1868), con el positivo realizado por Laurent a partir de la misma pintura. Véase Nigel Glendinning, ob. cit., pp. 21 y 22.

${ }^{28}$ Véase Charles Yriarte, ob. cit., p. 92.

${ }^{29}$ Se recogen las opiniones de los máximos expertos europeos en el artículo que escribí con la ayuda técnica de mi amigo, el arquitecto Rolfe Kentish. Véase «Goya's Country House in Madrid. The Quinta del Sordo», Apollo, CXXIII,

$A E A$, LXXVII, 2004, 307, pp. 233 a 245 

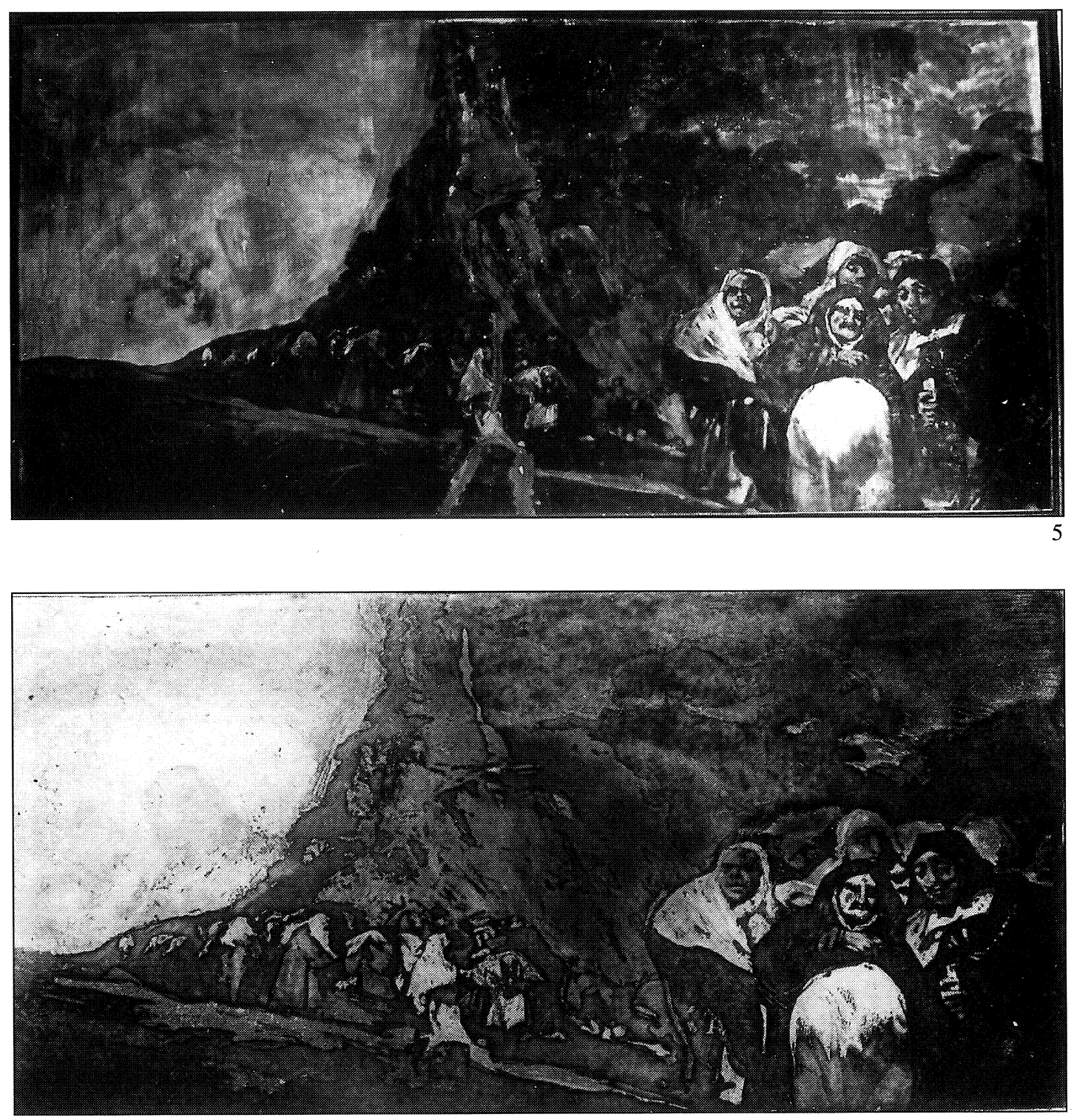

6

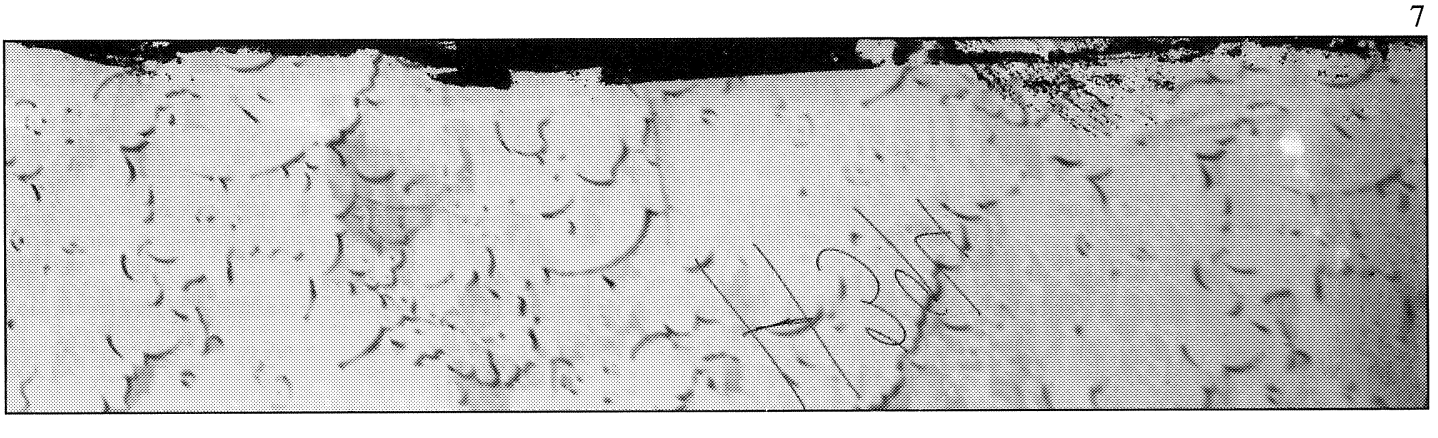

Fig. 5. Fotografía tomada por J. Laurent de El Santo Oficio (ca. 1864-1866). Madrid, Archivo Ruiz Vernacci, Instituto del Patrimonio Histórico Español. Ministerio de Cultura.

Fig. 6. El Santo Oficio, grabado por Gimeno para El Arte en España (1868).

Fig. 7. Papel felpado en la sala de la planta baja de la Quinta. Detalle de una fotografía tomada por J. Laurent (ca. 18641866). Madrid, Archivo Ruiz Vernacci, Instituto del Patrimonio Histórico Español. Ministerio de Cultura.

AEA, LXXVII, 2004, 307, pp. 233 a 245 
ellos, siguen tradiciones establecidas mucho antes de esta fecha, a nuestro parecer, y dado el creciente gusto por este género de adorno para las casas y palacios en España entre 1764 y $1818^{30}$, no es inverosímil que el mismo Goya haya escogido tales papeles para su Quinta. El profesor Junquera, en cambio, sin aducir prueba alguna que apoye su hipótesis, opina que los dos papeles fueron estampados mucho después, utilizando métodos más bien mecanizados -en Inglaterra probablemente- con cilindros metálicos en vez de tacos de madera. También asevera que estos papeles pueden ser los que adornaban el Museo del Prado, y no la casa de recreo del artista. Pero no nos ha explicado en qué salas se encontraban, ni cómo las grietas de las paredes se hayan prolongado por los marcos y a través de las pinturas mismas.

\section{Javier Goya, Mariano y Leocadia Zorrilla de Weiss}

Puesto que no hemos encontrado base alguna para las dudas expuestas por el profesor Junquera sobre la autenticidad de las Pinturas Negras y su ubicación en la Quinta, parece inútil seguirle los pasos en sus investigaciones sobre la familia de Goya después de la muerte del pintor. No ha aportado dato alguno nuevo sobre la actividad artística de Javier, que era menester documentar, desde luego, a la hora de atribuirle catorce pinturas de una fuerza expresiva increible, una audacia técnica extraordinaria, y - en el piso inferior- una obsesión evidente con la vejez. Lo que sabemos de Javier no parece compatible con una empresa artística de tanto fuste. Además, pintar Javier un conjunto de cuadros regido por Saturno, que preside la séptima y última edad del Hombre —o sea, la vida a partir de los setenta años ${ }^{31}$ - requeriría una capacidad imaginativa fuera de lo común, y una gran originalidad que no parecen características del hijo de Goya. Huelga decir que no se ha encontrado aún ningún cuadro firmado por Javier, ni pintura alguna en cuya ejecución consta que haya intervenido. Es cierto que se le concedió una pensión de doce mil reales el 6 de octubre de 1803, para emprender un viaje de estudios bajo la dirección de su padre. Pero, al año siguiente le encontramos con una colocación en Tesorería Mayor en la que le corresponde la plaza núm. 34, que deja vacante al salir del ministerio en el mes de marzo de $1804^{32}$. Puede que haya dejado, por lo tanto —con cierto retraso por cierto- un puesto de funcionario para dedicarse de repente al arte. Al casarse en 1805 , la partida de su casamiento en los libros parroquiales, le da por pintor ${ }^{33}$, pero poco después, se dedica nuevamente a las tareas administrativas y financieras, siendo la compraventa de casas, la administración de sus bienes, la ayuda económica a su hijo, y la conservación y venta de obras de su padre, lo que se le ha podido documentar. Se le designa «hacendado y labrador» y no pintor, al firmar en 1832 la escritura para hipotecar una de sus casas, con el fin de cubrir los gastos de la cultivación de la Huerta de Goya y otras tierras labrantías que le

\footnotetext{
No. 288,1986 , p. 108 , notas 25 y 26. En la opinion de Jean Hamilton, los dos papeles podían muy bien haberse fabricado antes de 1820. Ofrezco algunos nuevos argumentos estilísticos a favor de esta misma fecha en mi artículo «Goya's Black Paintings and the Wallpaper Mystery», de próxima aparición en The Wallpaper History Review, advirtiendo la existencia de diseños del mismo tipo y, en uno de los dos casos, de elementos idénticos, en papeles de los siglos XVII y xVIII.

30 Ya en 1764, Ramón de la Cruz se refería a la floreciente moda del papel pintado en su sainete «El Petimetre». En abril de 1818, la Gaceta de Madrid recoge una relación de la visita de la Familia Real a la Fábrica de Papel Pintado regida por Pedro Giroud en la villa y corte, y se dan más noticias sobre la misma fábrica el 2 de septiembre de 1819 , tan sólo seis meses después de la compra de la Quinta por Goya.

31 Véase Nigel Glendinning y Rolfe Kentish, art. cit., pp. 107-108.

32 Véase Matilla Tascón, A., «Documentos del Archivo del Ministerio de Hacienda, relativos a pintores de cámara, y de las Fábricas de Tapices y Porcelana. Siglo XVIII», Revista de Archivos, Bibliotecas y Museos, LXVIII, N. 1, 1960 , p. 227 (N. ${ }^{\circ}$ 96). Esta referencia se recogió en el Apéndice escrito por Xavier de Salas para el libro de Francisco Javier Sánchez Cantón, Goya and the Black Paintings, Londres, Faber \& Faber, 1964, p. 89, nota 92.

${ }^{33}$ Marqués del Saltillo, ob. cit., p. 67.
}

$A E A, \mathrm{LXXVII}, 2004,307$, pp. 233 a 245 
pertenecían, junto con su hijo Mariano ${ }^{34}$. Por mucho que supiera de las obras de su padre y su manera de trabajar, no hay nada que nos permita suponer que fuera capaz de pintar las catorce obras maestras que nos siguen apabullando y desconcertando a muchos, a pesar de los defectos producidos por el tiempo, la trasportación al lienzo y la primera restauración, y horrorizando aún, al parecer, a «los aficionados al Arte académico, justo, medido y acabado» ${ }^{35}$.

${ }^{34}$ Id., p. 41.

${ }^{35}$ Beruete y Moret, A., Conferencias de arte, Madrid, Blass, 1924, p. 365.

AEA, LXXVII, 2004, 307, pp. 233 a 245 